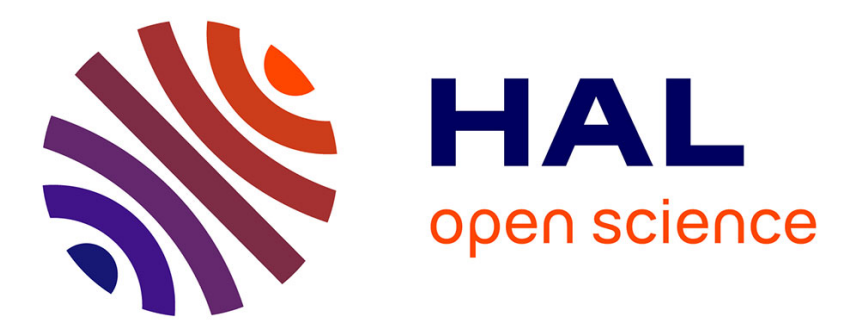

\title{
Methylerythritol Phosphate Pathway: Enzymatic Evidence for a Rotation in the LytB/IspH Catalyzed Reaction
}

Philippe Chaignon, Benoit Eric Petit, Bruno Vincent, Lionel Allouche, Myriam Seemann

\section{To cite this version:}

Philippe Chaignon, Benoit Eric Petit, Bruno Vincent, Lionel Allouche, Myriam Seemann. Methylerythritol Phosphate Pathway: Enzymatic Evidence for a Rotation in the LytB/IspH Catalyzed Reaction. Chemistry - A European Journal, 2019, 10.1002/chem.201904676 . hal-02407672

\section{HAL Id: hal-02407672 \\ https://hal.science/hal-02407672}

Submitted on 20 Nov 2020

HAL is a multi-disciplinary open access archive for the deposit and dissemination of scientific research documents, whether they are published or not. The documents may come from teaching and research institutions in France or abroad, or from public or private research centers.
L'archive ouverte pluridisciplinaire HAL, est destinée au dépôt et à la diffusion de documents scientifiques de niveau recherche, publiés ou non, émanant des établissements d'enseignement et de recherche français ou étrangers, des laboratoires publics ou privés. 
Methylerythritol Phosphate Pathway: Enzymatic Evidence for a Rotation in the LytB/IspH Catalyzed Reaction

Philippe Chaignon, [a] Benoît Eric Petit, [a] Bruno Vincent, [b] Lionel Allouche, [b] and Myriam Seemann *[a]

Abstract: IspH/LytB, an oxygen-sensitive [4Fe-4S] enzyme, catalyzes the last step of the methylerythritol phosphate (MEP) pathway, a target for the development of new antimicrobial agents. This metalloenzyme converts (E)-4-hydroxy-3-methylbut-2-en-1-yl diphosphate (HMBPP) into the two isoprenoid precursors: isopentenyl diphosphate (IPP) and dimethylallyl diphosphate (DMAPP). Here, we report the synthesis of (S)-[4-2H1]HMBPP and (R)-[4-2H1]HMBPP, and a detailed NMR analysis of the products formed after their respective incubation with $\mathrm{E}$. coli IspH/LytB in the presence of the biological reduction system used by E.coli to reduce the [4Fe-4S] center. (S)-[4-2H1]HMBPP was converted into [4-2H1]DMAPP and (E)-[4-2H1]IPP whereas (R)-[4-2H1]HMBPP yielded [4-2H1]DMAPP and (Z)-[4-2H1]IPP, hence providing the direct enzymatic evidence that the mechanism catalyzed by IspH/LytB involves a rotation of the $\mathrm{CH} 2 \mathrm{OH}$ group of the substrate to display it away from the [4Fe-4S].

Isoprenoids are found in all living organisms and include metabolites that are essential for life. They are biosynthesised according to the methylerythritol phosphate (MEP) pathway in most bacteria, including pathogenic like M. tuberculosis (responsible for tuberculosis) and opportunistic like K. pneumoniae, A. baumannii, P. aeruginosa (responsible for several hospital-acquired infections), in the malaria parasite Plasmodium falciparum and in plant chloroplasts.[1] As humans utilize exclusively the well-known mevalonate pathway for the production of these crucial molecules,[2] targeting the MEP pathway was proposed as an attractive strategy in the search for new antimicrobial agents. [3-6] Indeed, bacteria that are multiresistant against currently available antibiotics are emerging worldwide, hence the urgency to bring new compounds in the pipeline. In February 2017, WHO published a list of prioritization of bacteria to guide Research and Development of new antibiotics.[7] Interestingly, almost all the bacteria classified as critical or high priority rely on the MEP pathway.

In the last step of this biosynthetic route, IspH (also called LytB) converts (E)-4-hydroxy-3methylbut-2-en-1-yl diphosphate (HMBPP, 1) into a mixture of isopentenyl diphosphate (IPP, 2) and dimethylallyl diphosphate (DMAPP, 3), the two building blocks for all isoprenoids. IspH catalyses this reductive dehydroxylation by using an oxygen sensitive [4Fe-4S]2+ cluster. Mössbauer spectroscopy[8,9] and more recently Nuclear Resonance Vibrational Spectroscopy experiments revealed that the [4Fe-4S]2+ cluster of substrate-free IspH is peculiar as one of its four iron sites is in an octahedral coordination geometry, with three inorganic sulfur atoms of the iron sulfur cluster and three water molecules as ligands.[10] This unusual coordination with labile ligands is at the origin of the instability of IspH [4Fe-4S] cluster. It is now well established that the first step in the IspH mechanism is the binding of the $\mathrm{OH}$ group of the substrate to this apical iron[11,12] accompanied by the release of water molecules. [10] The IspH structure in complex with HMBPP showed that the $\mathrm{OH}$ group not only binds the apical iron but is also involved in a series of hydrogen bonds involving T167, E126, a water molecule and a phosphate of the substrate.[11] Next steps of the mechanism 
consisting in the removal of a hydroxyl group, transfer of two electrons from the reduced [4Fe-4S]1+ cluster, and protonation of an anionic allylic intermediate are still under discussion (Scheme 1). It was proposed that after reduction of the first bioinorganic complex (Scheme 1), the $\mathrm{OH}$ group of the substrate undergoes a rotation by almost $180^{\circ}$ to interact with E126 leading to a [?] fact that E126D and E126Q IspH mutants were shown to be inactive. It is unclear if T167 is involved in this rotation as Span and co-workers reported that the $\mathrm{T} 167 \mathrm{C} \mathrm{IspH}$ mutant retains moderate activity.[14] Intensive EPR/ENDOR investigations resulted in the characterization of an intermediate displaying spectroscopic properties similar to the [4Fe-4S]3+ cluster found in ferredoxin:thioredoxin reductase and was proposed to be a $\eta 3$-allyl $($ [?] [?]complex $[16,17]$ that forms after water elimination, supporting earlier evidence for the formation of a bioorganometallic intermediate based on RX crystallography.[11] Subsequent reduction of the paramagnetic $\eta 3$-allyl (? ? ? complex followed by protonation at the si face of $\mathrm{C}-2$ will yield IPP 2 while protonation at C-4 will yield DMAPP 3.[18]

Scheme 1. Mechanism proposed for the IspH/LytB catalysed reaction.

The above reduction/water elimination steps were investigated by EPR/ENDOR spectroscopy using $E$. coli and A. aeolicus IspH $[16,17,19]$ reduced with dithionite, or by crystallography.[11,14] An alternative conformation of the substrate with the OH group rotated and not oriented towards the $\mathrm{Fe} / \mathrm{S}$ center was observed in some mutants of IspH ([3Fe-4S] form) in complex with the substrate.[14] A similar alternative conformation of (E)-4amino-3-methylbut-2-en-1-yl diphosphate (AMBPP), a HMBPP analogue in which the $\mathrm{OH}$ group was replaced by an amino group, was also reported in a IspH:AMBPP complex structure (PDB ID: 4H4D).[20] However this conformation could not be observed in another independently reported structure of this complex (PDB ID: 3ZGL) in which the occupancy of the [4Fe-4S] was verified to be $100 \%$.[21] IspH contains a very oxygen sensitive [4Fe-4S] center that can dissociate (loss of the apical iron) during the crystallization process. Therefore, it cannot be excluded that the alternative conformation observed in some X-ray structures was due to the loss of this iron. Some indirect evidence for the rotation step was also provided by Dickschat and co-workers after feeding of several deuterated isotopologues of 1-deoxy-D-xylulose to $\mathrm{S}$. avermitilis followed by the analysis of deuterium contained in pentalenene,[15] a sesquiterpene produced by streptomycetes. However, it is still unclear whether this rotation occurs in bacteria other than $\mathrm{S}$. avermitilis as its direct validation on any IspH enzyme was not reported.

Here, we propose to provide strong evidence for this critical rotation step by incubating $E$. coli IspH enzyme in the presence of the natural biological reduction system $\mathrm{NADPH} /$ flavodoxine reductase/flavodoxine[22] used by most bacteria including $\mathrm{E}$. coli to continuously supply IspH with reducing equivalents for the reductive dihydroxylation, and either (S)-[4-2H1]HMBPP 4 or (R)-[4-2H1]HMBPP 5 as substrate. The configuration of the resulting [4-2H1]IPP product should clearly demonstrate if a rotation occurs in the IspH mechanism. 
The route to the [4-2H1]HMBPP enantiomers is outlined in Scheme 2 and was developed based on our previous synthesis of HMBPP[23] and of racemic [4-2H1] HMBPP, [24] except for the steps introducing the deuterium into the desired configuration.

Briefly, (E)-(S)-[4-2H1]HMBPP 4 and (E)-(R)-[4-2H1]HMBPP 5 were synthesized starting from ethyl (E)-4-hydroxy-2-methylbut-2-enoate 6 obtained as described in [23] but starting from ethyl 2-bromopropionate (Scheme S1 and S2). Subsequent chlorination of 6 with thionyl chloride and triethylamine in $\mathrm{CH} 2 \mathrm{Cl} 2$ afforded 7 (47\% yield).[25] Reduction of ester 7 with diisobutylaluminum deuteride in toluene led to $(\mathrm{E})-[1,1-2 \mathrm{H} 2]-4-c h l o r o-2-m e t h y l b u t-2-e n-1-o l$ 8 that was not isolated and directly oxidised with Dess Martin periodinane[26] yielding aldehyde 9 (88\% yield for the two steps). The key step in our synthesis of (S)-[4-2H1]HMBPP 4 was a selective reduction of aldehyde 9 with (R)-Alpine borane[27] providing (S)-[1-2H1]-4chloro-2-methylbut-2-en-1-ol 10 (yield 88\%).[28] The enantiomeric excess of 10 was about $92 \%$, as determined after esterification with (R)-MTPCl followed by $1 \mathrm{H} N M R$ analysis of the two resulting diastereoisomers. (S)-[4-2H1]HMBPP 4 was further obtained from the chiral alcohol 10 by treatment with tris(tetra-n-butylammonium) hydrogen as described by Poulter and co-workers.[24]

Similarly, (R)-[4-2H1]HMBPP 5 was obtained after reduction of aldehyde 9 with (S)-Alpine borane yielding (R)-[1-2H1]-4-chloro-2-methylbut-2-en-1-ol 11, 90\% ee) followed by phosphorylation.

Scheme 2. Synthesis of (S)-[4-2H1]HMBPP 4 and (R)-[4-2H1]HMBPP 5.

(i) $\mathrm{SOCl} 2, \mathrm{NEt} 3, \mathrm{CH} 2 \mathrm{Cl} 2,0^{\circ} \mathrm{C}$ to RT, (ii) DIBAL-D, THF, $-78^{\circ} \mathrm{C}$ to $\mathrm{RT}$, (iii) Dess Martin periodinane, $\mathrm{CH} 2 \mathrm{Cl} 2,0^{\circ} \mathrm{C}$ to $\mathrm{RT}$, (iv) (R)-Alpine borane, THF, (iv') (S)-Alpine borane, THF, (v) (nBu4N)3HP2O7, CH3CN.

E. coli IspH was produced, purified under anaerobic conditions and characterized as described previously.[21,29] The UV/visible spectrum, the iron and sulfur content and the activity $(750 \mathrm{nmol}$ min-1.mg-1) were in agreement with previously reported data[8,21,29] confirming that the $[4 \mathrm{Fe}-4 \mathrm{~S}]$ cluster was intact.

To further explore the rotation step in the IspH mechanism, the fate of the deuterium on C-4 of stereospecific labeled HMBPP was monitored using an IspH assay performed under anaerobic conditions in the presence of the biological reduction system. In the hypothesis a rotation would occur, (S)-[4-2H1]HMBPP 4 should be converted by IspH into a mixture of (E)[4-2H1]IPP 2a and [4-2H1]DMAPP 3a (Scheme 3) whereas (R)-[4-2H1]HMBPP 5 should provide (Z)-[4-2H1]IPP $2 \mathrm{~b}$ and [4-2H1]DMAPP $3 \mathrm{a}$.

Scheme 3. Fate of (S)-[4-2H1]HMBPP 4 in the hypothesis IspH mechanism involves a rotation step. The scheme for the conversion of 5 to $2 b$ and $3 a$ is given in $\mathrm{SI}$. 
(S)-[4-2H1]HMBPP 4 was incubated anaerobically with recombinant E. coli IspH in the presence of NADPH, flavodoxine reductase, flavodoxine and the course of the reaction was followed by monitoring the decrease of absorbance of NADPH at $340 \mathrm{~nm}$ (Fig.S1). Once the reaction was completed and the enzyme removed, the mixture containing both products was directly analyzed by $2 \mathrm{H}-\mathrm{NMR}$ spectroscopy. The spectrum displayed a peak at $\mathrm{l}=1.73 \mathrm{ppm}$ corresponding to the deuterium on the $\mathrm{C}-4$ of [4-2H1]DMAPP 3a (Fig. S2a).The peak corresponding to [4-2H1]IPP could however not be clearly observed as it was under the residual HOD solvent peak After solvent exchange to D2O, the $1 \mathrm{H}-\mathrm{NMR}$ spectrum of the incubation mixture was recorded and exhibited the predominant signal of the $\mathrm{CH} 3$ group of IPP (? = 1.78), that according to its integration was about 7 times more intense than the (Z)CH3 of DMAPP (]=1.73) which is in agreement with the IPP/DMAPP ratio reported in former assays. [30,31] The presence of a deuterium atom on C-4 of DMAPP was further confirmed by the presence of a signal at ? $=1.75$ that corresponds to the two protons of $(\mathrm{E})-\mathrm{CH} 2 \mathrm{D}$ of DMAPP. However, the C-4 proton of the resulting [4-2H1]IPP was not directly observable on the $1 \mathrm{H}-\mathrm{NMR}$ spectrum as it was under the HOD peak. Therefore, in order to determine the configuration of the double bound of [4-2H1]IPP formed in the incubation of (S)-[42H1]HMBPP 4 with IspH, a more complete NMR investigation was needed.

The $1 \mathrm{H}-13 \mathrm{C} \mathrm{HSQC}$ spectrum of the previous incubation revealed a triplet at $114.1 \mathrm{ppm}$ that correlates with a proton at $4.84 \mathrm{ppm}$ confirming the presence of a deuterium on the C-4 of [4-2H1]IPP (Fig.1a). It also showed a triplet at $27.54 \mathrm{ppm}$ with a correlation with a proton at 1.75 ppm confirming the formation of [4-2H1]DMAPP (Fig.S3). The exact position of the deuterium of [4-2H1]IPP was further investigated using NOESY correlations (Fig.1b). The methyl protons $(1.75 \mathrm{ppm})$ and $\mathrm{C}-1$ protons $(4,07 \mathrm{ppm})$ on one hand, the methylene proton at $\mathrm{C}-2(2.40 \mathrm{ppm})$ and the vinyl proton at C-4 $(4.84 \mathrm{ppm})$ on the other hand, showed positive cross peaks revealing the formation of (E)-[4-2H1]IPP 2a. The position of the deuterium in the trans position in [4-2H1]IPP was further confirmed on the HSQC-HECADE spectra (Fig.1c) that exhibited a large heteronuclear coupling constant between $\mathrm{H}-4$ (4.84ppm) and $\mathrm{CH} 3$ $(24.5 \mathrm{ppm}, 3 \mathrm{~J}(\mathrm{C}, \mathrm{H})=11.48 \mathrm{~Hz}$ ) confirming that $\mathrm{H}-4$ and the methyl group are in trans position, and a smaller heteronuclear coupling constant between $\mathrm{H}-4$ and $\mathrm{C}-2(40.71 \mathrm{ppm}, 3 \mathrm{~J}(\mathrm{C}, \mathrm{H}=$ $5.9 \mathrm{~Hz}$ ) indicating that $\mathrm{H}-4$ and $\mathrm{C}-2$ are in cis position. [32]

In a second experiment, (R)-[4-2H1]HMBPP 5 was incubated with IspH and the products of the reaction were similarly analyzed by NMR spectroscopy as for the other enantiomer. The resulting $1 \mathrm{H}-\mathrm{NMR}$ spectrum was almost identical to the spectrum obtained when (S)-[42H1]HMBPP 4 was incubated with IspH indicating the formation of [4-2H1]DMAPP 3a and a IPP/DMAPP ratio of about 7. The $1 \mathrm{H}-13 \mathrm{C}$ HSQC spectrum showed a triplet at $27.61 \mathrm{ppm}$ with a correlation with a proton at $1.75 \mathrm{ppm}$ confirming the formation of [4-2H1]DMAPP 3a The formation of [4-2H1]IPP was confirmed on the HSQC spectrum by the presence of a triplet at $114.1 \mathrm{ppm}$ that correlates with a proton at $4.86 \mathrm{ppm}$ (Fig.1d). No crosspeak between $\mathrm{H}-4$ (4.86 ppm) and $\mathrm{H}-2(2.40 \mathrm{ppm})$ were present on the NOESY spectrum whereas correlations were clearly observed between $\mathrm{H}-4(4.86 \mathrm{ppm})$ and methyl protons $(1.78 \mathrm{ppm})$ indicating the formation of (Z)-[4-2H1]IPP. Furthermore, the HSQC-HECADE spectrum displayed a heteronuclear coupling constant of $6.5 \mathrm{~Hz}$ between $\mathrm{H}-4$ (4.86 ppm) and $\mathrm{CH} 3(24.56 \mathrm{ppm})$ confirming that this two moieties are in cis position and hence that (Z)-[4-2H1]IPP was 
formed.[32] No crosspeak was observed between $\mathrm{H}-4$ and $\mathrm{C}-2$ even if this constant is expected to be around $10.5 \mathrm{~Hz}$. Most probably the TOCSY transfer between $\mathrm{H}-4$ and $\mathrm{H}-2$ is not efficient making the observation of the $3 \mathrm{~J}(\mathrm{H}-4, \mathrm{C}-2)$ not possible. A careful inspection of the $1 \mathrm{H}-\mathrm{RMN}$ spectrum of the reaction mixture revealed also that the methyl of IPP (1.78 ppm) appears as a doublet with a coupling constant of about $1.3 \mathrm{~Hz}$ and may represent a $\mathrm{W}$ coupling between the methyl and the C-4 proton in (Z)-[4-2H1]IPP. A W coupling between the methyl and the $\mathrm{C}-4$ proton would not occur in (E)-[4-2H1]IPP.

Figure 1. NMR spectra of the incubation of (S)-[4-2H1]HMBPP 4 (a) $1 \mathrm{H}-13 \mathrm{C} \mathrm{HSQC} \mathrm{b)} \mathrm{NOESY}$ c) $1 \mathrm{H}-13 \mathrm{C}$ HSQC HECADE) or (R)-[4-2H1]HMBPP 5 (d) $1 \mathrm{H}-13 \mathrm{C}$ HSQC e) NOESY f) $1 \mathrm{H}-13 \mathrm{C} \mathrm{HSQC}$ HECADE) with IspH.

In summary, IspH converts (S)-[4-2H1]HMBPP 4 into (E)-[4-2H1]IPP 2a, and (R)-[4$2 \mathrm{H} 1]$ HMBPP 5 into $(\mathrm{Z})$-[4-2H1]IPP providing strong evidence that the mechanism catalyzed by IspH involves a rotation of the $\mathrm{CH} 2 \mathrm{OH}$ of $\mathrm{HMBPP}$. Our enzymatic approach confirms the results obtained previously either indirectly using EPR or crystallography, or on S. avermitilis after feeding of deuterated isotopologues of 1-deoxy-D-xylulose. The parameters that drive this rotation are still a matter of debate. However, upon reduction, the apical iron might become softer leading to the exchange of the $\mathrm{OH}$ ligand for the softer alkene base allowing the $\mathrm{OH}$ group to rotate toward E126. Comparison of several structures of synthetic analogues of [4Fe-4S] clusters revealed that the [4Fe-4S]+ core has increased plasticity compared to the [4Fe-4S]2+ core and hence can adopt different distortions depending of its environment.[33] Therefore, it cannot be excluded that upon reduction, the [4Fe-4S] cluster might undergo a conformational change that could trigger this ligand exchange. Our investigation can be used more generally to investigate this rotation step in $\mathrm{E}$ coli and in other bacteria including pathogens and might give rise to novel strategies to fight infectious diseases.

\section{Experimental Section}

Experimental details are given in supporting information.

\section{Acknowledgements}

We are grateful to Prof. A. Boronat (University of Barcelona, Spain) and his group for providing us with the $\mathrm{E}$. coli strain overexpressing LytB. This work was supported by the 'Agence Nationale de la Recherche' (ANR-2011-BSV5-028), by the "Centre International de Recherche aux Frontières de la Chimie" and COST Action 1201 to M.S.

Keywords: • [4Fe-4S] cluster • Enzyme catalysis • IspH/LytB • Metalloenzyme • Methylerythritol phosphate pathway

[1] a) M. Rohmer, Nat. Prod. Rep. 1999, 16, 565-574; b) W. Eisenreich, F. Rohdich, A. Bacher, Trends Plant Sci. 2001, 6, 78-84.

[2] K. Bloch, Steroids 1992, 57, 378-383. 
[3] M. Rohmer, C. Grosdemange-Billiard, M. Seemann, D. Tritsch, Curr. Opin. Invest. Drugs 2004, 5, 154-162.

[4] T. Grawert, M. Groll, F. Rohdich, A. Bacher, W. Eisenreich, Cell Mol Life Sci, 2011 ,68, 3797-3814.

[5] L. Zhao, W. C. Chang, Y. Xiao, H. W. Liu, P. Liu, Annu Rev Biochem 2013, 82, 497-530.

[6] T. Masini, A. K. Hirsch, J Med Chem 2014, 57, 9740-9763.

[7] Prioritization of pathogens to guide discovery, research and development of new antibiotics for drug resistant bacterial infections, including tuberculosis. Report No. WHO/EMP/IAU/2017.12, (World Health Organization, 2017).

[8] M. Seemann, K. Janthawornpong, J. Schweizer, L. H. Böttger, A. Janoschka, A. AhrensBotzong, E. N. Tambou, O. Rotthaus, A. X. Trautwein, M. Rohmer, V. Schünemann, J. Am. Chem. Soc. 2009, 131, 13184-13185.

[9] Y. Xiao, L. Chu, Y. Sanakis, P. Liu, J. Am. Chem. Soc. 2009, 131, 9931-9933.

[10] I. Faus, A. Reinhard, S. Rackwitz, J. A. Wolny, K. Schlage, H.-C. Wille, A. Chumakov, S. Krasutsky, P. Chaignon, C. D. Poulter, M. Seemann, V. Schünemann, Angew. Chem. Int. Ed Engl. 2015, 54, 12584-12587.

[11] T. Gräwert, I. Span, W. Eisenreich, F. Rohdich, J. Eppinger, A. Bacher, M. Groll, Proc. Natl. Acad. Sci. 2010, 107, 1077-1081.

[12] A. Ahrens-Botzong, K. Janthawornpong, J.A. Wolny, E. N. Tambou, M. Rohmer, S. Krasutsky, C. D. Poulter, V. Schünemann, M. Seemann, Angew. Chem. Int. Ed. 2011, 50, 11976-11979

[13] W. Wang, K. Wang, Y. L. Liu, J. H. No, J. Li, M. J. Nilges, E. Oldfield, Proc Natl Acad Sci U S A 2010, 107, 4522-4527.

[14] I. Span, T. Grawert, A. Bacher, W. Eisenreich, M. Groll, J Mol Biol 2012, 416, 1-

9.

[15] C. A. Citron, N. L. Brock, P. Rabe, J. S. Dickschat, Angew Chem Int Ed Engl 2012, 51, 4053-4057.

[16] W. Xu, N. S. Lees, D. Hall, D. Welideniya, B. M. Hoffman, E. C. Duin, Biochemistry 2012, $51,4835-4849$.

[17] W. Wang, K. Wang, I. Span, J. Jauch, A. Bacher, M. Groll, E. Oldfield, J Am Chem Soc 2012, 134, 11225-11234.

[18] R. Laupitz, T. Gräwert, C. Rieder, F. Zepeck, A. Bacher, D. Arigoni, F. Rohdich, W. Eisenreich, Chem. Biodivers. 2004, 1, 1367-1376.

[19] J. Li, K. Wang, T. I. Smirnova, R. L. Khade, Y. Zhang, E. Oldfield, Angew Chem Int Ed Engl 2013, 52, 6522-6525.

[20I. Span, K. Wang, W. Wang, J. Jauch, W. Eisenreich, A. Bacher, E. Oldfield, M. Groll, Angew Chem Int Ed Engl 2013, 52, 2118-2121.

[21] F. Borel, E. Barbier, S. Krasutsky, K. Janthawornpong, P. Chaignon, C. D. Poulter, J. L. Ferrer, M. Seemann, Chembiochem 2017, 18, 2137-2144. 
[22] K. J. Puan, H. Wang, T. Dairi, T. Kuzuyama, C. T. Morita, FEBS Lett 2005, 579, 38023806.

[23] M. Wolff, M. Seemann, C. Grosdemange-Billiard, D. Tritsch, N. Campos, M. RodriguezConcepcion, A. Boronat, M. Rohmer, Tetrahedron Lett 2002, 43, 2555-2559.

[24] D. T. Fox, C. D. Poulter, J Org Chem 2002, 67, 5009-5010

[25] L. A. Brozek, M. J. Ardolino, J. P. Morken, J Am Chem Soc 2011, 133, 16778-16781.

[26] P. Sawant, M. E. Maier, Synlett 2011, 3002-3004.

[27] M.M. Midland, Chem Rev 1989, 1553-1561.

[28] O. S. Ascenso, J. C. Marques, A. R. Santos, K. B. Xavier, M. R. Ventura, C. D. Maycock, Bioorg Med Chem 2011, 19, 1236-1241.

[29] K. Janthawornpong, S. Krasutsky, P. Chaignon, M. Rohmer, C. D. Poulter, M. Seemann, J Am Chem Soc 2013, 135, 1816-1822

[30] T. Grawert, J. Kaiser, F. Zepeck, R. Laupitz, S. Hecht, S. Amslinger, N. Schramek, E. Schleicher, S. Weber, M. Haslbeck, J. Buchner, C. Rieder, D. Arigoni, A. Bacher, W. Eisenreich, F. Rohdich, J Am Chem Soc 2004, 126, 12847-12855.

[31] M. Wolff, M. Seemann, B. Tse Sum Bui, Y. Frapart, D. Tritsch, A. Garcia Estrabot, M. Rodriguez-Concepcion, A. Boronat, A. Marquet, M. Rohmer, FEBS Lett 2003, 541, 115-120.

[32] U. Vogeli, W. V. Philipsborn, Org Magn Resonance 1975, 7, 617-627. [33] P. Venkateswara Rao and R. H. Holm, Chem. Rev. 2004 104, 527-560

Entry for the Table of Contents

\section{COMMUNICATION}

Missing piece in the investigation of a rotation of the $\mathrm{CH} 2 \mathrm{OH}$ group of the substrate in the IspH/LytB mechanism

P.Chaignon, B.E. Petit, B. Vincent, L. Allouche, M. Seemann* Page No. - Page No.

Methylerythritol Phosphate Pathway: Enzymatic Evidence for a Rotation in the LytB/IspH Catalyzed Reaction 
